\title{
As CRISPR-Cas adoption soars, summit calls for genome editing oversight
}

Researchers are using a pair of initiatives, launched within a few days of each other, to widen the discussion about genome editing oversight to include countries often excluded from the conversation. At a meeting in Paris on March 23, a group of European biotech researchers launched the Association for Responsible Research and Innovation in Genome Editing (ARRIGE). Two days earlier, Nature published a call by two science, technology and society scholars to establish a global gene editing observatory (Nature 555, 435-437, 2018). The initiatives raise the questions of whether and how the research community should lead these discussions.

The dramatic adoption of CRISPR-Cas9 gene editing in laboratories around the world prompted the first discussions of the ethics of human genome editing. In December 2015, an International Summit on Human Gene Editing was convened by the US National Academies, the Royal Society in London and the Chinese Academy of Sciences in Washington, DC (Nature 528, 173, 2015). The summit's organizing committee produced a position statement at the end of the meeting. It did not condemn experiments to modify human embryos, but urged further discussions about safety and ethics, and efforts to harmonize regulation of the use of CRISPR-Cas9 and other genome editing technologies.

Thus far, members of the public and nonexperts have been part of the discussions, but with many countries and sections of society not

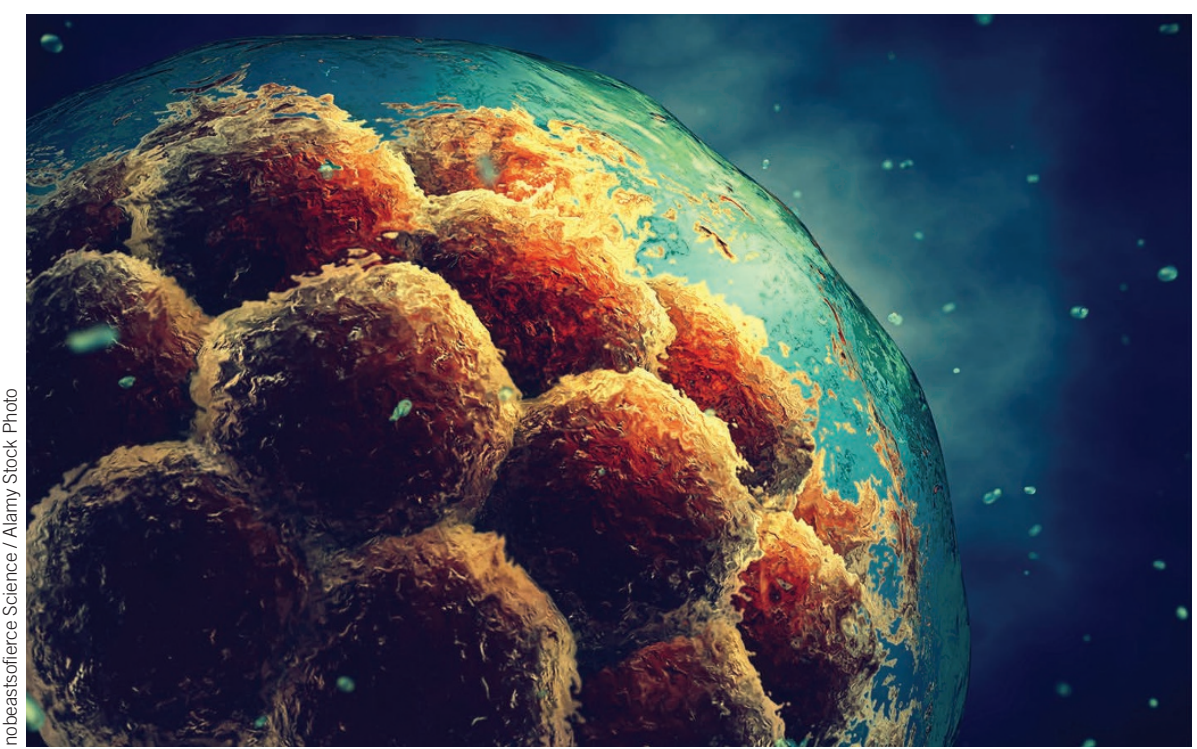

Researchers have used CRISPR-Cas9 to correct a disease-causing mutation in human embryos, but the research, though legal, pushes ethical boundaries. represented, there is a case for broader representation. "We can't get sufficient dialog going," says Arthur Caplan, a bioethicist with the New York University Langone Medical Center. "We need more forums than these." To address this shortcoming, France's Institut National de la Santé et de la Recherche Médicale (INSERM) convened a series of meetings that led to ARRIGE's formation. Lay people, patient associations, nongovernmental organizations, governmental agencies, funding bodies and companies must all be part of the discussion, says Lluis Montoliu, a researcher at Spain's National Biotechnology Center in Madrid and one of the ARRIGE founders.

To add diversity, it is important that the global South-India, Southeast Asia, subSaharan Africa and South America-is represented says Montoliu. This is because many of the more controversial developments, such as gene drives for disease-carrying mosquitoes, would be deployed in those regions. "Do they know what we are planning to do?" he says. "Are they part of this discussion? Do they understand? Do they really accept? Do they know the challenges that [are] posed to the environment [by] the release of these genomeedited mosquitoes?" Montoliu adds.

The gene editing 'observatory', proposed by Sheila Jasanoff, director of the Program on Science, Technology and Society at Harvard University, and Arizona State University bioethicist J. Benjamin Hurlbut, would be made up of an international network of scholars and

organizations. The network would be similar to those established for human rights and climate change, according to the authors. It would be "dedicated to gathering information from dispersed sources, bringing to the fore perspectives that are often overlooked, and promoting exchange across disciplinary and cultural divides," they wrote.

Organizations like ARRIGE promise that there will be more stakeholders at the table as the ethics of genome editing are worked out. This includes people who might be adversely affected by the technologies as well as those who might benefit from them, says Jasanoff. But even with diverse participants, framing the issue as a matter of risks, benefits and stakeholders is too limiting to cover the scope and consequences of technologies that have the potential to alter the nature of whole species, including humans, she says. Risk-benefit and stakeholder discussions tend to be couched in technical terms that describe measurable risks that can be assessed by experimental systems, says Jasanoff. They don't include moral and philosophical dimensions, she says. "Are we really prepared to say that something like therapy versus enhancement can be decided by one expert committee?"

The two proposed initiatives-ARRIGE and the genome editing observatory-are important, but more needs to be done, says NYU's Caplan. Part of the problem is the broad impact of genome editing technologies, he says. "It's hard to know sometimes who isn't a stakeholder-everyone has a stake in the future of genetics." Another part of the problem is the narrow range of current discussions. When researchers talk about the ethics of genome editing they tend to focus on controversial topics like germline editing and human enhancement. Researchers and other stakeholders need to work out the issues of editing microbe and animal genomes, Caplan says, citing experiments on the virulence of pathogens and potential alterations to animals that humans consume.

Even as companies focus on complying with regulations governing the development and commercialization of gene therapies, the biotech industry should engage in these discussions, says Sandy Macrae, CEO of gene-therapy biotech Sangamo Therapeutics. "There needs to be a very clear alignment between patients, investigators, companies like ours and society at large," he says. "It would be a mistake for us to think that we can do this in a vacuum."

Eric Smalley Boston 